Article

\title{
Adverse Events of Intravesical OnabotulinumtoxinA Injection between Patients with Overactive Bladder and Interstitial Cystitis-Different Mechanisms of Action of Botox on Bladder Dysfunction?
}

\author{
Yuh-Chen Kuo ${ }^{1,2}$ and Hann-Chorng Kuo ${ }^{2, *}$ \\ 1 Department of Urology, Yangming Branch of Taipei City Hospital, Taipei 11146, Taiwan; \\ yuhchens@hotmail.com \\ 2 Department of Urology, Buddhist Tzu Chi General Hospital and Tzu Chi University, Taipei 11146, Taiwan \\ * Correspondence: hck@tzuchi.com.tw; Tel.: +886-3-856-1825 (ext. 2117); Fax: +886-3-856-0794
}

Academic Editors: Joseph Jankovic and Flaminia Pavone

Received: 17 January 2016; Accepted: 7 March 2016; Published: 16 March 2016

\begin{abstract}
Intravesical onabotulinumtoxinA (BoNT-A) injections have been proposed to treat both overactive bladder (OAB) and interstitial cystitis/bladder pain syndrome (IC/BPS) in patients with refractory conditions. We compared adverse events (AEs) after BoNT-A treatment between IC/BPS and $\mathrm{OAB}$ in women. IC/BPS patients who failed conventional treatments were enrolled to receive suburothelial injections of BoNT-A (100 U) followed by hydrodistention. Age matched OAB female patients refractory to antimuscarinic agents underwent BoNT-A (100 U) injections. The bladder capacity, maximum flow rate (Qmax), post-void residual (PVR), and voiding efficiency (VE) at baseline, 3 and 6 months, and the post-treatment AEs were analyzed between groups. Finally, $89 \mathrm{IC} / \mathrm{BPS}$ and $72 \mathrm{OAB}$ women were included. In the OAB group, the bladder capacity and PVR increased, and VE decreased significantly at three and six months after BoNT-A treatment. In the IC/BPS group, the Qmax increased significantly at six months. There were significant differences in changes of capacity, Qmax, PVR and VE between the two groups. Moreover, OAB patients suffered more frequently from events of hematuria, UTI, and large PVR $(>200 \mathrm{~mL})$, but less frequently from events of straining to void. In conclusion, OAB women had higher PVR volume and lower VE than those in IC/BPS after BoNT-A injections. These results imply that the bladder contractility of OAB patients are more susceptible to BoNT-A, which might reflect the different mechanisms of action of Botox on bladder dysfunction. Further investigations to confirm this hypothesis are warranted.
\end{abstract}

Keywords: onabotulinumtoxinA; adverse events; interstitial cystitis; overactive bladder

\section{Introduction}

Overactive bladder $(\mathrm{OAB})$ is a symptom syndrome characterized by urinary urgency, usually accompanied by frequency and nocturia, with or without urgency urinary incontinence, in the absence of a urinary tract infection (UTI) or other obvious pathology [1]. OAB symptoms can be quite bothersome and can negatively affect health-related quality of life (HR-QoL), increase anxiety and depression, and increase healthcare usage [2,3]. The cause of OAB is unclear, and indeed there may be multiple causes [4]. It is often associated with overactivity of the detrusor muscle, a pattern of bladder muscle contraction observed during urodynamics, which may be neurogenic, myogenic, urotheliogenic or idiopathic in origin [5].

Intravesical injection of onabotulinumtoxinA (BoNT-A) is approved by the Food and Drug Administration for treatment of $\mathrm{OAB}$ refractory to antimuscarinic agents. Several randomized placebo-controlled studies have demonstrated that BoNT-A (100 U) was well tolerated and resulted in 
significantly and clinically relevant improvements in all OAB symptoms, patient-reported benefits, and HR-QoL in patients inadequately managed by anticholinergic drugs [6-9]. However, there still exist substantial incidences of various treatment-related adverse events (AEs) $(20 \%-43 \%)$ [10]. Acute urinary retention (AUR), large postvoid residual (PVR), difficulty in urination, and UTI are common AEs.

Interstitial cystitis/bladder pain syndrome (IC/BPS) is a clinical diagnosis based on symptoms including urinary frequency, urgency and bladder pain, pressure, and/or discomfort in the absence of other pathologic findings [11]. Although urothelial dysfunction, mast cell activation, neurogenic inflammation and C-fiber neuroplasticity are proposed to be the causes of IC/BPS [12], the pathogenesis of IC/BPS is not fully understood so far. The management of IC/BPS is mainly directed to amelioration of the bothersome symptoms such as bladder pain or urinary tract symptoms.

Intravesical botulinum toxin A has been suggested to be administered in IC/BPS patients if other treatments have not provided adequate symptom control and quality of life [13]. Recent studies have demonstrated the therapeutic effects of BoNT-A on the symptom relief of IC/BPS [14-17]. Common AEs included dysuria, the need for abdominal straining to void, large PVR, and the need for clean intermittent self-catheterization (CISC). However, the morbidity substantially reduced if the dose used was shifted from 200 to $100 \mathrm{U}$ [13].

Although OAB and IC/BPS are different disease entities, intravesical BoNT-A injection was used to treat both syndromes in subjects with refractory conditions. In addition to telling the patients the advantage of the therapy, it is necessary to disclose the possible AEs before the procedures. The American Urological Association (AUA) guidelines for OAB and IC/BPS stated that the patients must be able and willing to perform, or accept the possibility of, CISC if BoNT-A injections are planned to be offered $[13,18]$. Considering the different nature of the diseases, it makes one curious to know if there any difference in the distribution of BoNT-A related AEs between the two groups of patients, which may be important in patient counseling before the treatment and might reflect the mechanisms of action of BoNT-A in the two syndromes. Thus, we conducted this study to compare AEs of intravesical BoNT-A injections between OAB and IC/BPS in women.

\section{Results}

\subsection{Demographics}

Eighty-nine women (aged $48.81 \pm 11.81$ ) with IC/BPS and 72 (aged $49.15 \pm 10.85$ ) with OAB were included in this study. The patient characteristics are listed in Table 1. At baseline, there was no significant difference in the mean age and most urodynamic parameters between the two groups. Exceptions were the significantly higher mean functional bladder capacity (FBC), day time frequency, nocturia, maximum flow rate (Qmax), and detrusor pressure at Qmax (Pdet) in the OAB group when compared with those in the IC/BPS group, showing the distinct nature of the two syndromes.

Table 1. Characteristics of study patients.

\begin{tabular}{|c|c|c|c|}
\hline Group & OAB $(N=72)$ & IC/BPS $(N=89)$ & $p$ \\
\hline Age (years) & $49.15 \pm 10.85$ & $48.81 \pm 11.81$ & 0.777 \\
\hline Functional bladder capacity (mL) & $351.43 \pm 135.21$ & $124.72 \pm 76.91$ & $0.000 *$ \\
\hline Daytime frequency (times/day) & $34.05 \pm 14.56$ & $15.64 \pm 7.88$ & $0.000 *$ \\
\hline Nocturia (times/night) & $8.05 \pm 2.99$ & $4.90 \pm 4.93$ & $0.009 *$ \\
\hline Urgency (times $/ 24 \mathrm{~h}$ ) & $33.00 \pm 17.87$ & - & - \\
\hline Urge urinary incontinence (times $/ 24 \mathrm{~h}$ ) & $10.57 \pm 12.98$ & - & - \\
\hline Visual analogue scale & - & $5.43 \pm 2.24$ & - \\
\hline Maximum flow rate (Qmax) (mL/s) & $15.73 \pm 9.69$ & $12.62 \pm 5.48$ & $0.012 *$ \\
\hline Voided volume $(\mathrm{mL})$ & $224.86 \pm 122.24$ & $244.41 \pm 112.12$ & 0.364 \\
\hline Postvoid residual (mL) & $39.19 \pm 100.28$ & $38.01 \pm 93.26$ & 0.916 \\
\hline Total bladder capacity (mL) & $260.93 \pm 143.25$ & $266.19 \pm 117.15$ & 0.800 \\
\hline Voiding efficiency & $0.88 \pm 0.20$ & $0.85 \pm 0.30$ & 0.577 \\
\hline First sensation of filling (mL) & $112.14 \pm 68.90$ & $117.33 \pm 53.28$ & 0.744 \\
\hline Strong desire to void (mL) & $210.86 \pm 120.41$ & $197.45 \pm 87.74$ & 0.597 \\
\hline Cystometric bladder capacity $(\mathrm{mL})$ & $264.61 \pm 145.28$ & $274.72 \pm 109.92$ & 0.714 \\
\hline Detrusor pressure at Qmax $\left(\mathrm{cm} \mathrm{H}_{2} \mathrm{O}\right)$ & $27.49 \pm 13.60$ & $19.19 \pm 10.65$ & $0.000 *$ \\
\hline
\end{tabular}

$* p<0.05$. Independent $t$ test. 


\subsection{Effects of Botulinum Toxin A on Voiding Function}

At six months after BoNT-A injections, the mean Overactive Bladder Symptom Score, urge incontinence episode, urgency episode and day time frequency decreased significantly in OAB patients. There was an overall successful rate of $51.4 \%$ (24 dry and 13 with increase of Patient's Perception of Bladder Condition score $\geqslant 2$ ) [19]. In the IC/BPS group, the mean O'Leary-Sant Symptom Index and Problem Index, pain visual analogue scale, daytime frequency and nocturia decreased and functional bladder capacity increased significantly at six months, making an overall successful rate of $46.1 \%$ (41 with a Global Response Assessment score $\geqslant 2$ ) [20].

Figure 1 shows changes in the bladder capacity, Qmax, PVR, and voiding efficiency (VE) from baseline to six months after BoNT-A injections in OAB and IC/BPS patients. In the OAB group, the PVR and bladder capacity peaked and the VE decreased significantly at three months, and did not return to baseline level at six months. There was no significant change of Qmax within the six-month follow-up period. In the IC/BPS group, there was no change in the bladder capacity, PVR, and VE from baseline to six months after BoNT-A injections. Interestingly, the Qmax increased significantly at six months.
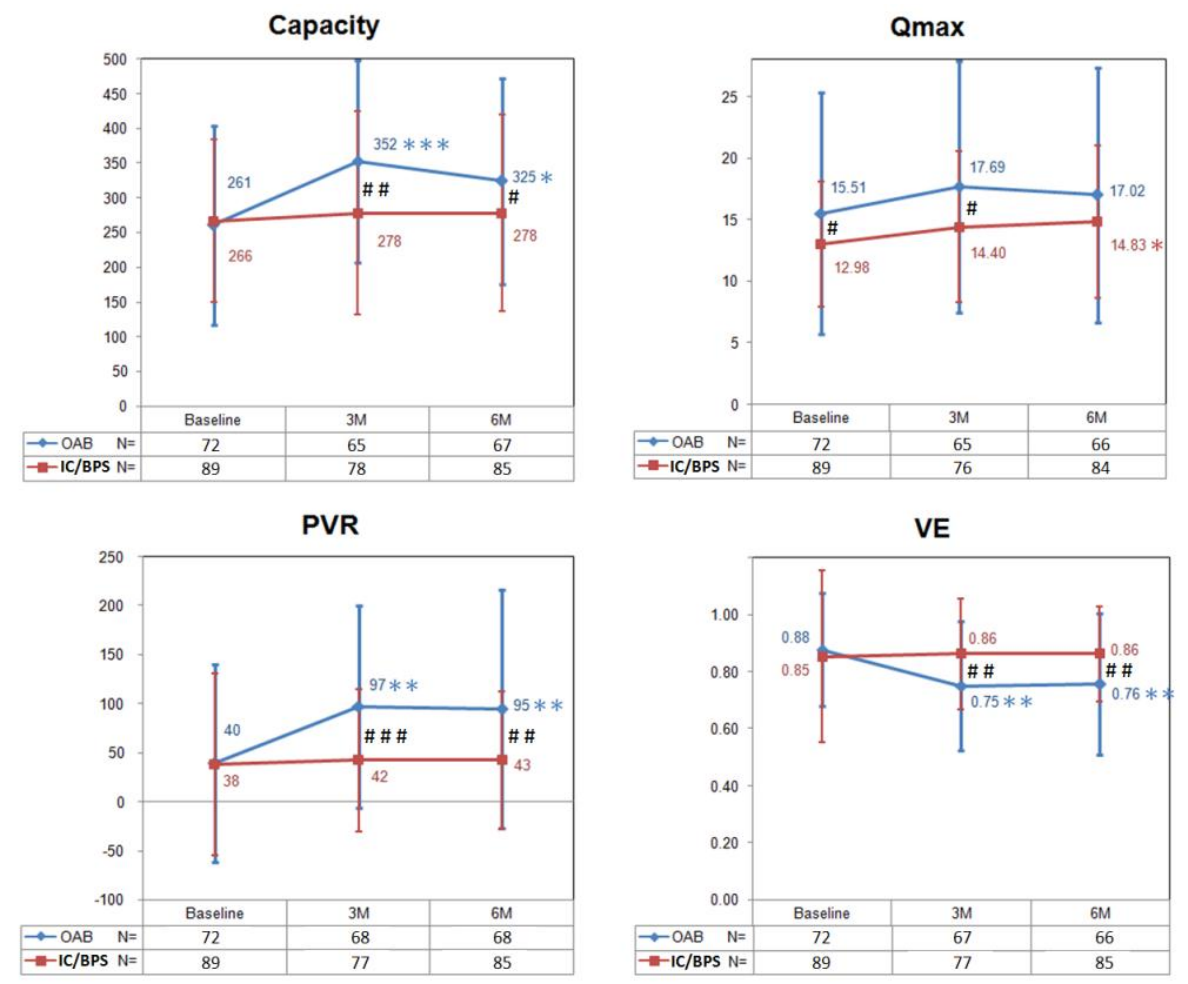

Figure 1. The changes of bladder capacity, maximum flow rate (Qmax), postvoid residual (PVR), and voiding efficiency $(\mathrm{VE})$ in patients with overactive bladder $(\mathrm{OAB})$ and interstitial cystitis/bladder pain syndrome (IC/BPS) after BoNT-A injections. Data are expressed as mean \pm standard deviation. ${ }^{*} p<0.05,{ }^{* *} p<0.01,{ }^{* * *} p<0.001$ when compared with baseline data in each group. Paired $t$ test was used. ${ }^{\#} p<0.05,{ }^{\# \#} p<0.01,{ }^{\# \#} p<0.001$ when compared between groups. Independent $t$ test was used.

Taking these data together, there were significant differences in changes of capacity, Qmax, PVR and VE between the two groups (Figure 1). Patients in the OAB group had larger bladder capacity, PVR and lower VE at three and six months after BoNT-A injections when compared with those in the IC/BPS group. Comparing with the OAB group, the Qmax in the IC/BPS group was significantly lower at baseline but "recovered" at six months after BoNT-A injections. 


\subsection{Adverse Events after Botulinum Toxin A Injections}

During the follow-up period, $58.3 \%$ of $\mathrm{OAB}$ women reported at least one $\mathrm{AE}$, including gross hematuria $(9.7 \%)$, UTI $(27.8 \%)$, straining to void $(8.3 \%)$, large PVR (>200 $\mathrm{mL})(31.9 \%)$ and AUR $(1.4 \%)$. On the other hand, $42.7 \%$ of IC /BPS patients found at least one AE, including UTI (6.7\%), straining to void $(30.3 \%)$ and large PVR $(6.7 \%)$. There was no gross hematuria nor AUR experienced (Table 2). These data demonstrated the overall incidence of AEs was significantly higher in the OAB group than in the IC/BPS group. Patients in the OAB group suffered more frequently from events of hematuria, UTI, and large PVR but less frequently from event of straining to void than those in the IC/BPS group. There was no significant difference in events of AUR between the two groups.

Table 2. The adverse events in patients with overactive bladder and interstitial cystitis/bladder pain syndrome.

\begin{tabular}{cccc}
\hline Adverse Events & OAB (\%) & IC/BPS (\%) & $p$ \\
\hline Hematuria & $7(9.7)$ & $0(0)$ & $0.003^{\mathrm{a}}$ \\
UTI & $20(27.8)$ & $6(6.7)$ & $0.000^{\mathrm{a}}$ \\
Straining to void & $6(8.3)$ & $27(30.3)$ & $0.001^{\mathrm{a}}$ \\
PVR > 200 mL & $23(31.9)$ & $6(6.7)$ & $0.000^{\mathrm{a}}$ \\
AUR & $1(1.4)$ & $0(0)$ & 0.265 \\
Any & $42(58.3)$ & $38(42.7)$ & $0.048^{\mathrm{b}}$
\end{tabular}

a Pearson chi-square with Fisher exact correction; ${ }^{b}$ Pearson chi-square test. UTI: urinary tract infection. PVR: postvoid residual. AUR: acute urinary retention.

\section{Discussion}

To our knowledge, this is the first study to compare the BoNT-A injection related AEs between $\mathrm{OAB}$ and IC/BPS patients. Our data demonstrated that by injecting $100 \mathrm{U}$ of BoNT-A into the suburothelial space, the volume of bladder capacity and PVR increased, and the VE decreased significantly in women with OAB than those with IC/BPS within a six-month follow-up period. These results imply that the contractility of bladder in $\mathrm{OAB}$ patients might be more susceptible to BoNT-A injection than that in IC/BPS.

Although BoNT-A was applied to the treatment of both OAB and IC/BPS, the mechanisms of action may be different between these two syndromes because of their different pathophysiology. Intravesical injection of BoNT-A has been introduced to treat refractory IC/BPS since 2004 [21]. BoNT-A acts by cleaving the synaptosome-associated protein of $25 \mathrm{kd}$ complex in the presynaptic terminal, which prevents formation of the SNARE system and then the release of neurotransmitter vesicles at the synaptic cleft. Consequently, the release of acetylcholine, calcitonin gene-related protein, substance-P and glutamate decreased and thus the nociceptive fiber discharge reduced [22], suggesting the therapeutic rationale of BoNT-A on IC/BPS. Furthermore, recent studies have demonstrated that BoNT-A has an anti-inflammatory effect on a cystitis rat model [23] and that injection of BoNT-A can reduce the production of nerve growth factor in the bladder resulting in satisfactory pain relief in IC/PBS patients [24,25].

In the last decade, intravesical injection of BoNT-A emerged as an effective treatment for OAB among patients refractory or intolerant to antimuscarinic agents [26]. BoNT-A significantly improves $\mathrm{OAB}$ symptoms and urodynamic parameters in OAB patients. The clinical efficacy of BoNT-A may be explained by its proposed dual mechanism of action in targeting both the afferent and efferent neuronal pathways of bladder control. BoNT-A can not only block the release of acetylcholine and other neurotransmitters from nerve fibers but also from urothelium. In addition, BoNT-A may decrease the expression of sensory receptors $[27,28]$. Since increased release of acetylcholine from neuronal and nonneuronal (urothelial) sources in the bladder during the storage phase was proposed to contribute to the pathophysiology of detrusor overactivity (DO) [29,30], which is the main target of BoNT-A injection, there is no wonder that the bladder contractility in OAB patients is more easily affected by 
BoNT-A injection than that in IC/BPS, resulting in higher volume of bladder capacity and PVR, and lower VE in OAB patients. This phenomenon suggests there might be different mechanisms of action of BoNT-A on the two syndromes, yet further investigations to compare the changes of sensory or motor proteins in the OAB and IC/BPS bladder before and after BoNT-A treatment are warranted.

Our data also disclosed that the Qmax in the IC/BPS group was significantly lower at baseline, but was raised to as high as in the OAB group at six months after BoNT-A injections. It has been well established that visceral pain syndromes, including irritable bowel syndrome, endometriosis, and IC/BPS, may be associated with non-relaxing pelvic floor muscles through central and peripheral sensitization and lowering of nociceptive thresholds, resulting in neuropathic up-regulation, hypersensitivity, allodynia and dysfunctional voiding [31]. Intravesical injection of BoNT-A may reduce the pain symptom and neurogenic inflammation inside the pelvis [23-25,32], and thus release the non-relaxing pelvic floor muscles and improve the dysfunctional voiding in IC/BPS patients.

When comparing the rates of AEs after BoNT-A injections between the two groups, we found that patients in the OAB group had higher incidences of hematuria, UTI, and large PVR, but lower incidence of straining to void than those in the IC/BPS group. Only one OAB and no IC/BPS patient experienced AUR. Although our result showed no significant difference in event of AUR between the two groups, $31.9 \%$ of OAB vs. $6.7 \%$ of IC/BPS women had large PVR ( $>200 \mathrm{~mL})$, which is compatible with the change of voiding function after BoNT-A injections in both groups. Again, higher percentage of large PVR in the OAB group indicates its vulnerable nature to BoNT-A injections. In addition, UTIs have been reported in between $2 \%$ and $32 \%$ of OAB patients treated, and are usually associated with a large PVR volume [33], explaining the higher incidence of UTIs in OAB patients. It is difficult to clarify why OAB women experienced hematuria more frequently than IC/BPS. Since five of the seven $(71 \%)$ OAB patients who had hematuria also experienced UTIs, the finding that the OAB group had higher incidence of hematuria may partly be a confounding result of UTIs. Moreover, chronic inflammation resulting in more advanced fibrosis in the suburothelial space in IC/BPS patients may account for these findings in part.

Since the FDA-approved dose of BoNT-A for OAB treatment is $100 \mathrm{U}$, some AEs appear to occur less frequently in comparison with previous studies using higher doses [18]. For example, rates of urinary retention have decreased from $43 \%$ to $<20 \%$. Similarly, the percent of patients requiring CISC have decreased from $43 \%$ to less than $10 \%$. However, recent studies using $100 \mathrm{U}$ of BoNT-A to treat IC/BPS revealed a much lower percentage $(0 \%-2 \%)$ of patients either suffering from urine retention or needing CISC $[15,17,34,35]$. The most common AE appeared to be dysuria. The current study also demonstrated that $30.3 \%$ of IC / BPS patients experienced straining to void. Only $6.7 \%$ had large PVR and none had urine retention, suggesting that the bladder contractility in IC/BPS patients seems being less interfered by BoNT-A injection. Although the AUA guideline statement addressing the possibility of CISC post-treatment in IC/BPS patients cannot be defeated at present [13], the very low incidence of urine retention and need for CISC may encourage the physicians and patients to receive BoNT-A injections, and help in the counseling before treatment.

One may criticize the use of hydrodistention (HD) in IC/BPS patients to be the major weakness in the comparison of AE between the two disorders in this study. BoNT-A injections followed by HD has been proved to be more effective than HD alone in treating IC/BPS in our previous prospective, randomized study [16]. In order to achieve the optimal therapeutic effect, we routinely use this method to treat our IC/BPS patients. However, the above study also demonstrated that HD alone could only improve the subjective parameters (IC symptom scores) but not objective (voiding diary or urodynamic) parameters and that the $\mathrm{AE}$ caused by HD was minimal (only one kind of AE, dysuria, presented in one out of 23 patients). Hence, the influence of HD on the comparison of voiding function and AEs after BoNT-A injections between OAB and IC/BPS women in this study is expected to be very limited. 
Other limitations of this study are data from single center, nonconsecutive enrollment of patients, and a lack of comparing comorbidities and its retrospective nature. Nevertheless, the male patients have been excluded and the patients' ages have been adjusted between the two groups to minimize the confounding risk factors for voiding dysfunction.

\section{Materials and Methods}

\subsection{Patient Enrollment}

In this retrospective study, female patients with IC/BPS were retrieved from a database containing one hundred four subjects who have undergone intravesical BoNT-A injection followed by hydrodistention from 2005 to 2013 . They had been treated with oral pentosan polysulfate sodium, intravesical instillation of heparin, hyaluronic acid, or oral tricyclic antidepressant for at least 6 months, but the symptoms remained unchanged or relapsed. A diagnosis of IC/BPS has been established based on characteristic symptoms and cystoscopic findings of glomerulation, petechia, or mucosal ulceration [36].

Previous studies have revealed that male gender, age $>61$ years old, those with a baseline Qmax $\leqslant 15 \mathrm{~mL} / \mathrm{sec}, \mathrm{PVR} \geqslant 100 \mathrm{~mL}$, and VE $<90 \%$ are risk factors of urine retention developed after BoNT-A injections in $\mathrm{OAB}$ patients [10,37]. Since patients with OAB are generally older and consisting of a higher percentage of males than those with IC/BPS, we excluded the male patients in both study groups. And only age-matching females with $\mathrm{OAB}$ were selected from a database consisting of 290 idiopathic DO subjects for comparing the effects of BoNT-A injection on voiding function and AEs. They have received intravesical BoNT-A injections from 2005 to 2014 . These patients had undergone life style modification therapy and treatment with at least two antimuscarinic agents for more than 3 months, but they were still bothered by severe urgency (defined as urgency severity score of 3) or urge urinary incontinence, resulting in a low quality of life. The detailed instruction for patient selection from the two databases is shown in Figure 2.

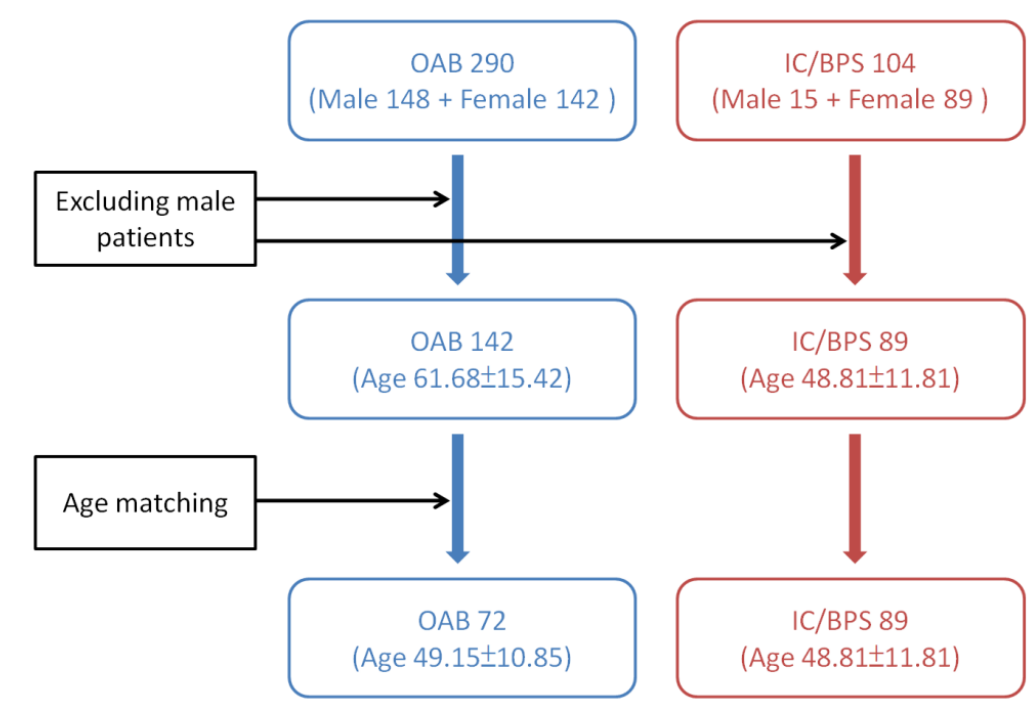

Figure 2. Instruction of patient selection from the databases of overactive bladder $(\mathrm{OAB})$ and interstitial cystitis/bladder pain syndrome (IC/BPS).

\subsection{Botulinum Toxin Injections}

All the patients received intravesical suburothelial injections of a total of $100 \mathrm{U}$ of BoNT-A at 20 to 40 sites in the bladder body, excluding the trigone. In IC/BPS patients, cystoscopic hydrodistention was performed to an intravesical pressure of $80 \mathrm{~cm}$ water for $15 \mathrm{~min}$ immediately after the injections. The detailed technique for suburothelial injection was described in previous reports [32,38]. 


\subsection{Patient Follow-Up}

Overactive Bladder Symptom Score for the OAB group, O'Leary-Sant Symptom and Problem Index and pain visual analog scale for the IC/BPS group, and 3-day voiding diary were recorded at baseline and every follow-up time point. Videourodynamic study was routinely performed at baseline. The cystometric bladder capacity, Pdet, Qmax, and PVR were recorded. During the follow-up period, uroflowmetry for Qmax, voided volume, and PVR were measured at each visit. The total bladder capacity was calculated by summation of the voided volume and PVR. The VE was calculated as the ratio of voided volume of the total bladder capacity. The total bladder capacity, Qmax, PVR and VE were used to analyze the occurrence of AEs within 6 months after BoNT-A treatment.

All patients were closely monitored at 2 weeks, 1 month, 3 months, and every month thereafter until the response to BoNT-A disappeared. Procedure-related AEs were recorded during the 6-month follow-up period after BoNT-A treatment. AEs included AUR (patients had severe difficulty in urination with PVR $>350 \mathrm{~mL}$ and an indwelling catheter or CISC was necessary); gross hematuria; large PVR ( $>200 \mathrm{~mL}$ ); straining to void (feeling difficulty urinating and needing abdominal straining to empty the bladder, which was not experienced prior to treatment); and UTIs (symptomatic or asymptomatic with white blood cell count $>10 /$ high power field in urinalysis).

\subsection{Statistical Analysis}

The changes in total bladder capacity, Qmax, PVR and VE and the incidences of AEs during the follow-up period were analyzed and compared between patients in OAB and IC/BPS groups. Statistical comparisons between the groups were tested using a chi-square test for categorical variables, and an independent $t$ or paired $t$ test for continuous variables. Statistical analyses were performed using SPSS 18.0 statistical software (SPSS Inc., Chicago, IL, USA).

\section{Conclusions}

Patients in the OAB group had higher PVR volume and lower VE than those in the IC/BPS group after BoNT-A treatment. These results imply that the bladder contractility of OAB women might be more susceptible to BoNT-A, which might reflect the different mechanisms of action of BoNT-A on bladder dysfunction. Further investigations to compare the changes of sensory or motor proteins in the OAB and IC/BPS bladder at baseline and after BoNT-A treatment might provide evidence for this speculation.

Author Contributions: Y.-C.K. analyzed data and was the primary author of the manuscript. H.-C.K. designed, oversaw, and performed the experiment and supervised the manuscript.

Conflicts of Interest: The authors declare no conflict of interest.

\section{Abbreviations}

The following abbreviations are used in this manuscript:

$\begin{array}{ll}\text { OAB } & \text { overactive bladder } \\ \text { UTI } & \begin{array}{l}\text { orinary tract infection } \\ \text { onabotulinumtoxinA } \\ \text { BoNT-A }\end{array} \\ \text { health-related quality of life } \\ \text { AE } & \text { adverse event } \\ \text { AUR } & \text { acute urinary retention } \\ \text { PVR } & \text { postvoid residual } \\ \text { IC/BPS } & \text { interstitial cystitis/bladder pain syndrome } \\ \text { CISC } & \text { clean intermittent self-catheterization } \\ \text { AUA } & \text { American Urological Association }\end{array}$


FBC

Qmax

Pdet

VE

DO

HD functional bladder capacity

maximum flow rate

detrusor pressure at Qmax

voiding efficiency

detrusor overactivity

hydrodistention

\section{References}

1. Haylen, B.T.; Freeman, R.M.; Swift, S.E.; Cosson, M.; Davila, G.W.; Deprest, J.; Dwyer, P.L.; Fatton, B.; Kocjancic, E.; Lee, J.; et al. An international urogynecological association (iuga)/international continence society (ics) joint terminology and classification of the complications related directly to the insertion of prostheses (meshes, implants, tapes) and grafts in female pelvic floor surgery. Neurourol. Urodyn. 2011, 30, 2-12. [PubMed]

2. Irwin, D.E.; Milsom, I.; Hunskaar, S.; Reilly, K.; Kopp, Z.; Herschorn, S.; Coyne, K.; Kelleher, C.; Hampel, C.; Artibani, W.; et al. Population-based survey of urinary incontinence, overactive bladder, and other lower urinary tract symptoms in five countries: Results of the epic study. Eur. Urol. 2006, 50, 1306-1314. [CrossRef] [PubMed]

3. Malmsten, U.G.; Molander, U.; Peeker, R.; Irwin, D.E.; Milsom, I. Urinary incontinence, overactive bladder, and other lower urinary tract symptoms: A longitudinal population-based survey in men aged 45-103 years. Eur. Urol. 2010, 58, 149-156. [CrossRef] [PubMed]

4. Wein, A.J.; Rackley, R.R. Overactive bladder: A better understanding of pathophysiology, diagnosis and management. J. Urol. 2006, 175, S5-S10. [CrossRef]

5. Meng, E.; Lin, W.-Y.; Lee, W.-C.; Chuang, Y.-C. Pathophysiology of overactive bladder. LUTS Low. Urin. Tract Symptoms 2012, 4, 48-55. [CrossRef] [PubMed]

6. Fowler, C.J.; Auerbach, S.; Ginsberg, D.; Hale, D.; Radziszewski, P.; Rechberger, T.; Patel, V.D.; Zhou, J.; Thompson, C.; Kowalski, J.W. Onabotulinumtoxina improves health-related quality of life in patients with urinary incontinence due to idiopathic overactive bladder: A 36-week, double-blind, placebo-controlled, randomized, dose-ranging trial. Eur. Urol. 2012, 62, 148-157. [CrossRef] [PubMed]

7. Kuo, H.C. Reduction of urgency severity is associated with long-term therapeutic effect after intravesical onabotulinumtoxin a injection for idiopathic detrusor overactivity. Neurourol. Urodyn. 2011, 30, 1497-1502. [CrossRef] [PubMed]

8. Mohee, A.; Khan, A.; Harris, N.; Eardley, I. Long-term outcome of the use of intravesical botulinum toxin for the treatment of overactive bladder (oab). BJU Int. 2013, 111, 106-113. [CrossRef] [PubMed]

9. Nitti, V.W.; Dmochowski, R.; Herschorn, S.; Sand, P.; Thompson, C.; Nardo, C.; Yan, X.; Haag-Molkenteller, C. Onabotulinumtoxina for the treatment of patients with overactive bladder and urinary incontinence: Results of a phase 3, randomized, placebo controlled trial. J. Urol. 2013, 189, 2186-2193. [CrossRef] [PubMed]

10. Kuo, H.C.; Liao, C.H.; Chung, S.D. Adverse events of intravesical botulinum toxin a injections for idiopathic detrusor overactivity: Risk factors and influence on treatment outcome. Eur. Urol. 2010, 58, 919-926. [CrossRef] [PubMed]

11. Propert, K.J.; Schaeffer, A.J.; Brensinger, C.M.; Kusek, J.W.; Nyberg, L.M.; Landis, J.R. A prospective study of interstitial cystitis: Results of longitudinal followup of the interstitial cystitis data base cohort. The interstitial cystitis data base study group. J. Urol. 2000, 163, 1434-1439. [CrossRef]

12. Butrick, C.W. Interstitial cystitis and chronic pelvic pain: New insights in neuropathology, diagnosis, and treatment. Clin. Obstet. Gynecol. 2003, 46, 811-823. [CrossRef] [PubMed]

13. Hanno, P.M.; Erickson, D.; Moldwin, R.; Faraday, M.M. Diagnosis and treatment of interstitial cystitis/bladder pain syndrome: Aua guideline amendment. J. Urol. 2015, 193, 1545-1553. [CrossRef] [PubMed]

14. Giannantoni, A.; Mearini, E.; Del Zingaro, M.; Proietti, S.; Porena, M. Two-year efficacy and safety of botulinum a toxin intravesical injections in patients affected by refractory painful bladder syndrome. Curr. Drug Deliv. 2010, 7, 1-4. [CrossRef] [PubMed] 
15. Kuo, H.C. Repeated onabotulinumtoxin-a injections provide better results than single injection in treatment of painful bladder syndrome. Pain physician 2013, 16, E15-E23. [PubMed]

16. Kuo, H.C.; Chancellor, M.B. Comparison of intravesical botulinum toxin type a injections plus hydrodistention with hydrodistention alone for the treatment of refractory interstitial cystitis/painful bladder syndrome. BJU Int. 2009, 104, 657-661. [PubMed]

17. Pinto, R.; Lopes, T.; Silva, J.; Silva, C.; Dinis, P.; Cruz, F. Persistent therapeutic effect of repeated injections of onabotulinum toxin a in refractory bladder pain syndrome/interstitial cystitis. J. Urol. 2013, 189, 548-553. [CrossRef] [PubMed]

18. Gormley, E.A.; Lightner, D.J.; Burgio, K.L.; Chai, T.C.; Clemens, J.Q.; Culkin, D.J.; Das, A.K.; Foster, H.E., Jr.; Scarpero, H.M.; Tessier, C.D.; et al. Diagnosis and treatment of overactive bladder (non-neurogenic) in adults: Aua/sufu guideline. J. Urol. 2012, 188, 2455-2463. [CrossRef] [PubMed]

19. Coyne, K.S.; Matza, L.S.; Kopp, Z.; Abrams, P. The validation of the patient perception of bladder condition (ppbc): A single-item global measure for patients with overactive bladder. Eur. Urol. 2006, 49, 1079-1086. [CrossRef] [PubMed]

20. Propert, K.J.; Mayer, R.D.; Wang, Y.; Sant, G.R.; Hanno, P.M.; Peters, K.M.; Kusek, J.W. Responsiveness of symptom scales for interstitial cystitis. Urology 2006, 67, 55-59. [CrossRef] [PubMed]

21. Smith, C.P.; Radziszewski, P.; Borkowski, A.; Somogyi, G.T.; Boone, T.B.; Chancellor, M.B. Botulinum toxin a has antinociceptive effects in treating interstitial cystitis. Urology 2004, 64, 871-875; discussion 875. [CrossRef] [PubMed]

22. Meng, J.; Wang, J.; Lawrence, G.; Dolly, J.O. Synaptobrevin i mediates exocytosis of cgrp from sensory neurons and inhibition by botulinum toxins reflects their anti-nociceptive potential. J. Cell Sci. 2007, 120, 2864-2874. [CrossRef] [PubMed]

23. Lucioni, A.; Bales, G.T.; Lotan, T.L.; McGehee, D.S.; Cook, S.P.; Rapp, D.E. Botulinum toxin type a inhibits sensory neuropeptide release in rat bladder models of acute injury and chronic inflammation. BJU Int. 2008, 101, 366-370. [CrossRef] [PubMed]

24. Liu, H.T.; Kuo, H.C. Intravesical botulinum toxin a injections plus hydrodistension can reduce nerve growth factor production and control bladder pain in interstitial cystitis. Urology 2007, 70, 463-468. [CrossRef] [PubMed]

25. Liu, H.T.; Tyagi, P.; Chancellor, M.B.; Kuo, H.C. Urinary nerve growth factor level is increased in patients with interstitial cystitis/bladder pain syndrome and decreased in responders to treatment. BJU Int. 2009, 104, 1476-1481. [CrossRef] [PubMed]

26. Chapple, C.; Sievert, K.D.; MacDiarmid, S.; Khullar, V.; Radziszewski, P.; Nardo, C.; Thompson, C.; Zhou, J.; Haag-Molkenteller, C. Onabotulinumtoxina $100 \mathrm{u}$ significantly improves all idiopathic overactive bladder symptoms and quality of life in patients with overactive bladder and urinary incontinence: A randomised, double-blind, placebo-controlled trial. Eur. Urol. 2013, 64, 249-256. [CrossRef] [PubMed]

27. Mangera, A.; Andersson, K.E.; Apostolidis, A.; Chapple, C.; Dasgupta, P.; Giannantoni, A.; Gravas, S.; Madersbacher, S. Contemporary management of lower urinary tract disease with botulinum toxin a: A systematic review of botox (onabotulinumtoxina) and dysport (abobotulinumtoxina). Eur. Urol. 2011, 60, 784-795. [CrossRef] [PubMed]

28. Yokoyama, T.; Chancellor, M.B.; Oguma, K.; Yamamoto, Y.; Suzuki, T.; Kumon, H.; Nagai, A. Botulinum toxin type a for the treatment of lower urinary tract disorders. Int. J. Urol. Off. J. Jpn. Urol. Assoc. 2012, 19, 202-215. [CrossRef] [PubMed]

29. Yoshida, M.; Miyamae, K.; Iwashita, H.; Otani, M.; Inadome, A. Management of detrusor dysfunction in the elderly: Changes in acetylcholine and adenosine triphosphate release during aging. Urology 2004, 63, 17-23. [CrossRef] [PubMed]

30. Mukerji, G.; Yiangou, Y.; Grogono, J.; Underwood, J.; Agarwal, S.K.; Khullar, V.; Anand, P. Localization of m2 and $\mathrm{m} 3$ muscarinic receptors in human bladder disorders and their clinical correlations. J. Urol. 2006, 176, 367-373. [CrossRef]

31. Faubion, S.S.; Shuster, L.T.; Bharucha, A.E. Recognition and management of nonrelaxing pelvic floor dysfunction. Mayo Clin. Proc. 2012, 87, 187-193. [CrossRef] [PubMed]

32. Kuo, Y.-C.; Kuo, H.-C. O'leary-Sant symptom index predicts the treatment outcome for onabotulinumtoxin a injections for refractory interstitial cystitis/bladder pain syndrome. Toxins 2015, 7, 2860-2871. [CrossRef] [PubMed] 
33. Karsenty, G.; Denys, P.; Amarenco, G.; De Seze, M.; Game, X.; Haab, F.; Kerdraon, J.; Perrouin-Verbe, B.; Ruffion, A.; Saussine, C.; et al. Botulinum toxin a (botox) intradetrusor injections in adults with neurogenic detrusor overactivity/neurogenic overactive bladder: A systematic literature review. Eur. Urol. 2008, 53, 275-287. [CrossRef] [PubMed]

34. Chung, S.D.; Kuo, Y.C.; Kuo, H.C. Intravesical onabotulinumtoxina injections for refractory painful bladder syndrome. Pain physician 2012, 15, 197-202. [PubMed]

35. Pinto, R.; Lopes, T.; Frias, B.; Silva, A.; Silva, J.A.; Silva, C.M.; Cruz, C.; Cruz, F.; Dinis, P. Trigonal injection of botulinum toxin a in patients with refractory bladder pain syndrome/interstitial cystitis. Eur. Urol. 2010, 58, 360-365. [CrossRef] [PubMed]

36. Homma, Y.; Ueda, T.; Tomoe, H.; Lin, A.T.; Kuo, H.C.; Lee, M.H.; Lee, J.G.; Kim, D.Y.; Lee, K.S. Clinical guidelines for interstitial cystitis and hypersensitive bladder syndrome. Int. J. Urol. Off. J. Jpn. Urol. Assoc. 2009, 16, 597-615. [CrossRef] [PubMed]

37. Jiang, Y.H.; Ong, H.L.; Kuo, H.C. Predictive factors of adverse events after intravesical suburothelial onabotulinumtoxina injections for overactive bladder syndrome-a real-life practice of 290 cases in a single center. Neurourol. Urodyn. 2015. [CrossRef] [PubMed]

38. Kuo, H.C. Comparison of effectiveness of detrusor, suburothelial and bladder base injections of botulinum toxin a for idiopathic detrusor overactivity. J. Urol. 2007, 178, 1359-1363. [CrossRef] [PubMed]

(C) 2016 by the authors; licensee MDPI, Basel, Switzerland. This article is an open access article distributed under the terms and conditions of the Creative Commons by Attribution (CC-BY) license (http:/ / creativecommons.org/licenses/by/4.0/). 